\title{
Major improvement of altimetry sea level estimations using pressure-derived corrections based on ERA-Interim atmospheric reanalysis
}

\author{
Loren Carrere, Yannice Faugère, and Michaël Ablain \\ Collecte Localisation Satellites, Parc Technologique du Canal, 8-10 rue Hermès, 31520 Ramonville-Saint-Agne, France \\ Correspondence to: Loren Carrere (lcarrere@cls.fr)
}

Received: 22 December 2015 - Published in Ocean Sci. Discuss.: 18 January 2016

Revised: 12 May 2016 - Accepted: 23 May 2016 - Published: 27 June 2016

\begin{abstract}
The new dynamic atmospheric correction (DAC) and dry tropospheric (DT) correction derived from the ERAInterim meteorological reanalysis have been computed for the 1992-2013 altimeter period. Using these new corrections significantly improves sea level estimations for short temporal signals ( $<2$ months); the impact is stronger if considering old altimeter missions (ERS-1, ERS-2, and Topex/Poseidon), for which DAC_ERA (DAC derived from ERA-Interim meteorological reanalysis) allows reduction of the along-track altimeter sea surface height (SSH) error by more than $3 \mathrm{~cm}$ in the Southern Ocean and in some shallow water regions. The impact of DT_ERA (DT derived from ERA-Interim meteorological reanalysis) is also significant in the southern high latitudes for these missions.

Concerning more recent missions (Jason-1, Jason-2, and Envisat), results are very similar between ERA-Interim and ECMWF-based corrections: on average for the global ocean, the operational DAC becomes slightly better than DAC_ERA only from the year 2006, likely due to the switch of the operational forcing to a higher spatial resolution. At regional scale, both DACs are similar in the deep ocean but DAC_ERA raises the residual crossovers' variance in some shallow water regions, indicating a slight degradation in the most recent years of the study. In the second decade of altimetry, unexpectedly DT_ERA still gives better results compared to the operational DT.

Concerning climate signals, both DAC_ERA and DT_ERA have a low impact on global mean sea level rise (MSL) trends, but they can have a strong impact on longterm regional trends' estimation, up to several millimeters per year locally.
\end{abstract}

\section{Introduction}

Since the 1990s, several altimeter missions have been monitoring the sea level at a global scale. Thanks to its current accuracy and maturity, altimetry is now considered as a fully operational and accurate observing system dedicated to scientific and operational applications, among which understanding the global climate change and the related global mean sea level rise (MSL) and mesoscale applications are a priority.

Satellite altimetry has shown its efficiency in detecting early changes in the global and regional MSL trends (Willis and Church, 2012; Cazenave et al., 2014). However, ensuring the long-term consistency and stability of altimeter measurements from one or several missions is challenging.

The global MSL trend has been determined to be around $3.2 \mathrm{~mm} \mathrm{yr}^{-1}$ over the period 1993-2008, with an uncertainty of $0.5 \mathrm{~mm} \mathrm{yr}^{-1}$ (Ablain et al., 2009, 2015) mostly explained by the orbit errors (Couhert et al., 2014), the aging of the altimeters' instruments, the drifts detected in radiometer wet tropospheric correction (Legeais et al., 2014), and uncertainties due to geophysical corrections.

In order to access the targeted ocean signal, altimeter measurements are corrected from several instrumental and geophysical corrections including the dry tropospheric correction (DT), and the dynamic atmospheric correction (DAC) which is one of the most critical after the tide correction.

The accuracy of DAC has been deeply improved during the last 20 years. First, because the ocean has a clear dynamic response to atmospheric forcing at high frequencies and when considering large scales (Vinogradova et al., 2007; Mathers and Woodworth, 2001; Ponte and Gaspar, 1999; 
Willebrand et al., 1980), taking into account that a DAC instead of a static inverse barometer correction (IB) allowed a very significant improvement of the altimetry product (Carrere and Lyard, 2003). Then, the quality of the DAC has increased from 2007 thanks to a better bathymetry field and a higher-resolution mesh (Carrere et al., 2007). Still, significant errors remain mostly due to a lack of resolution of the model (in shelf seas but also in some deep ocean regions), to remaining bathymetry errors and also due to atmospheric forcing field uncertainties (Lamouroux et al., 2006; Lamouroux, 2006; Greenberg et al., 2007).

In this context, the main objective of the sea level CCI project (Ablain et al., 2015) was to build improved long-term altimeter sea level data records dedicated to climate studies. For that purpose, several algorithms (instrumental parameters, orbit calculation, radiometer wet tropospheric correction, atmospheric corrections derived from model, oceanic tidal corrections, sea state bias, etc.) were developed to improve altimetry data and the processing to merge altimeter missions together.

Concerning the pressure-derived DAC and DT corrections, one of the main issues comes from the fact that the ECMWF operational analyses used to force the barotropic model are not compliant with climate and MSL applications. The stability is not ensured because many jumps exist in the meteorological temporal series due to ECMWF model evolutions or upgrades; Ablain et al. (2009) showed a significant impact of these jumps on the trends of the IB and the dry tropospheric corrections which both depend on the atmospheric pressure field. Moreover, the quality of the operational meteorological data set is not homogeneous for the entire altimeter period: early years are less accurate because of the use of old versions of the analysis system (ECMWF, 2016) and this may impact the estimation of mesoscale signals for the oldest years (Carrere, 2003).

The methodology adopted is to use the ERA-Interim meteorological reanalysis (Dee et al., 2011) to compute the new corrections (hereafter, DAC_ERA and DT_ERA) and analyze their impact on sea level estimation at climate scales, as well as at lower temporal scales for mesoscale applications. The main advantage of using meteorological reanalysis is the homogeneous quality of the temporal series, but at the cost of a lower spatial resolution.

After a complete description of the data sets and the methods of comparison in Sect. 2, we present an analysis of the differences of the atmospheric pressure-derived corrections in Sect. 3, and the impact of the new DAC_ERA and DT_ERA corrections on ocean short-scale signals in Sect. 4. Section 5 is dedicated to ocean long-term climate signals and Sect. 6 gathers the discussion and concluding remarks.
Table 1. Cycles used for the analysis of each altimeter mission.

\begin{tabular}{lll}
\hline Mission & Cycles used & Period \\
\hline Topex/Poseidon & $11-481$ & $31 / 12 / 1992-08 / 10 / 2005$ \\
Jason-1 & $1-330$ & $15 / 01 / 2002-26 / 12 / 2010$ \\
Jason-2 & $1-200$ & $12 / 07 / 2008-16 / 12 / 2013$ \\
ERS-1 & $15-27$ and $41-53$ & $23 / 10 / 1992-02 / 06 / 1996$ \\
ERS-2 & $1-85$ & $15 / 05 / 1995-02 / 07 / 2003$ \\
Envisat & $10-93$ & $30 / 09 / 2002-18 / 10 / 2010$ \\
\hline
\end{tabular}

\section{Description of the data sets and method}

\subsection{Altimeter data}

The altimeter measurements used were produced by Ssalto/Duacs and are distributed by Archiving, Validation, Interpretation of Satellite Oceanographic data (AVISO, 2011), with support from CNES (http://www.aviso.altimetry.fr/en/data/products/ sea-surface-height-products/global.html). Particularly, we have considered level 2 altimetric products, with $1 \mathrm{~Hz}$ along-track resolution, usually called geophysical data records (GDRs).

The altimeter period (from 1993) is sampled by six altimeter missions available on two different long-term tracks: TOPEX/Poseidon (TP in the text and in figures), Jason-1 (J1 in the figures), and Jason-2 (J2 in the figures), which are the reference missions flying on the reference TP track with a 10-day cycle; and ERS-1 (E1 in the figures), ERS-2 (E2 in the figures), and Envisat (EN in the figures), which fly on a sun-synchronous orbit with a 35-day cycle. The cycles used for the present study are listed in Table 1.

The different missions have been homogenized (Ablain et al., 2015) and the temporal series of TP, Jason-1, and Jason2 on one hand, and ERS-1, ERS-2, and Envisat on the other hand, have been concatenated to produce two long-term altimeter time series as described in Fig. 1. Nearly 20 years of data for each different orbit have been used for the present study, from 1993 onwards.

The altimeter sea surface height ( $\mathrm{SSH})$ is defined as the difference between orbit and range, corrected from several instrumental and geophysical corrections:

$$
\mathrm{SSH}=\text { orbit }- \text { range }-\mathrm{DAC}-\mathrm{DT}-\text { tide }- \text { other_corr }
$$

where

- DAC is the dynamic atmospheric correction studied in this paper; DT is the dry tropospheric correction also studied in this paper.

- Tide includes de the geocentric tide, the solid Earth tide, and the pole tide corrections. The geocentric tide correction comes from GOT4.7 model (Ray, 1999). 


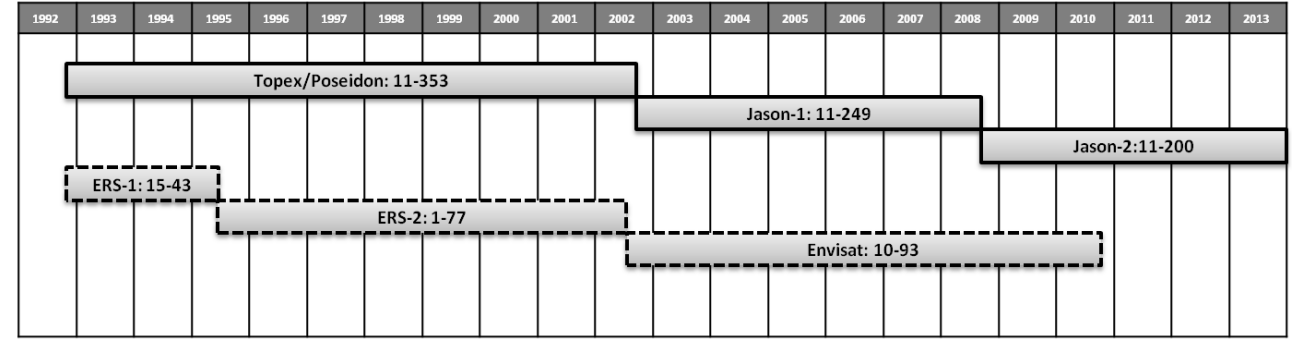

Figure 1. Altimeter long-term time series used in the study.

- Other_corr includes the wet tropospheric correction, the ionospheric correction, the sea state bias correction, and complementary instrumental corrections if needed.

- The sea level anomaly (SLA) is defined by the difference between SSH and a mean profile (MP) for repetitive orbits or a mean sea surface (MSS) for drifting or new orbits. Mean profiles computed for the reference period of 7 years (1993-1999), respectively for TPJason and ERS-Envisat orbits, have been used for the present study (Hernandez and Schaeffer, 2001).

\subsection{ERA-Interim data set}

The ERA-Interim meteorological data set is the latest global atmospheric reanalysis produced by the European Centre for Medium-Range Weather Forecasts (ECMWF). Nearly 34 years of data (from 1 January 1979) are available on the N128 Gaussian grid (equivalent to $\sim 0.7^{\circ}$ ), which is the native resolution chosen for the reanalysis. More details about the configuration and the performances of the system are given in the ERA-Interim reanalysis report (Dee et al., 2011). When compared to the ECMWF operational analysis, ERA-Interim benefits from a constant resolution and a constant model version which makes it very useful for climate studies in particular. ERA-Interim resolution is better than the operational one on the first years of altimetry $\left(0.7^{\circ}\right.$ instead of $\left.1^{\circ}\right)$. Sixhourly ERA-Interim analysis grids of sea level pressure and $10 \mathrm{~m}$ wind speeds have been used for the study.

\subsection{The dynamic atmospheric correction}

The high-frequency (HF) ocean signal forced by the atmosphere has a strong variability and is mostly located at high latitudes and in shallow water regions (Willebrand et al., 1980; Mathers, 2001); it is mostly barotropic if considering large spatial scales (Vinogradova et al., 2007). This HF signal is aliased into the lower-frequency band due to the bad temporal sampling of satellite altimeters (time revisit of 10 days for TP-Jason altimeters); if not corrected, this signal thus pollutes ocean circulation estimations from altimetry for mesoscale or climate applications and also for satellite calibration campaigns. This HF ocean variability thus needs to be corrected from an independent geophysical correction with centimetric accuracy (Stammer et al., 2000).

Since 2004, the dynamic atmospheric correction is used in altimeter GDRs; it is a combination of the high frequencies of MOG2D-G barotropic model forced by pressure and wind (Carrere, 2003) and the low frequencies (LF) of the inverted barometer, assuming a static response of the ocean to atmospheric forcing for low frequencies. The filtering wavelength is based on the TP/Jason-1/Jason-2 Nyquist frequency of 20 days (twice a cycle length), because this correction is primarily a de-aliasing correction made for reference altimeter missions (Carrere and Lyard, 2003).

$$
\mathrm{DAC}=\mathrm{MOG} 2 \mathrm{D}-\mathrm{G}_{\mathrm{HF}(T \leq 20 \text { days })}+\mathrm{IB}_{\mathrm{LF}(T>20 \text { days })}
$$

As far as ERS and Envisat missions are concerned, the sampling Nyquist period is 70 days which means that the DAC does not remove all atmospheric forced high-frequency signals aliased in the data. For altimeter multi-mission products (AVISO, 2011), remaining aliased signals are smoothed thanks to a long wavelength error correction; however, for mono-mission products like GDRs, these signals remain aliased in lower-frequency signals and can interfere with climate/seasonal variability (Carrere et al., 2010).

The reference DAC correction is computed from the $6 \mathrm{~h}$ ECMWF operational analysis (sea level pressure and $10 \mathrm{~m}$ winds) as done in CNES/AVISO data set (AVISO, 2011; Carrere and Lyard, 2003). The reference DAC is DAC_ECMWF hereafter.

\subsubsection{Processing of $\mathrm{S} 1$ and $\mathrm{S} 2$ atmospheric tides}

As far the dynamic atmospheric correction for altimetry is concerned, the diurnal (S1) and semidiurnal (S2) atmospheric tides demand a specific processing because they generate radiational tides at the same frequencies of the diurnal and semidiurnal ocean tides. As the radiational and the gravitational components cannot be well separated from observations, both components are included in global ocean tide models; thus, the radiational tides should not be also included in the DAC correction to avoid redundancy when correcting altimetry data.

The methodology chosen to correct the operational DAC from S1 and S2 radiational tides and make it complemen- 
tary to the ocean tide correction, is based on Ponte and Ray (2002); it consists of removing S1 and S2 atmospheric pressure climatologies from the DAC forcing. Climatologies computed from 11 years of operational ECMWF data (19932003; Carrere, 2005) are used for the operational DAC, but they are not coherent with the ERA-Interim data set. New monthly climatologies based on 18 years of ERA-Interim pressure data (1992-2009) have been computed and then removed from the DAC pressure forcing for the present study.

Figure 2 shows the difference between the new ERAInterim pressure climatology and the one used for operational DAC: differences are lower than $100 \mathrm{~Pa}$ over oceans and can be stronger on land.

\subsubsection{The new dynamic atmospheric correction derived from ERA-Interim}

The ERA-Interim DAC correction (DAC_ERA) has been computed while forcing the MOG2D barotropic ocean model with the corrected ERA-Interim meteorological data described above. The interest of using an atmospheric model reanalysis is to improve the quality of DAC for the oldest years and thus improve the homogeneity of the correction for the entire altimetric period; improving homogeneity helps with estimating more accurate trends. The same postprocessing as the one used for the reference DAC (20-day filtering) has been performed. The new correction has been computed for the 1991-2013 altimetric period.

\subsection{The dry tropospheric correction}

The propagation velocity of a radio pulse is slowed by dry gases and the quantity of water vapor in the Earth's troposphere. The dry gas contribution is nearly constant and produces height errors of approximately $-2.3 \mathrm{~m}$. This effect can be modeled as the gases in the troposphere contribute to the index of refraction. In details, the refractive index depends on pressure and temperature. When hydrostatic equilibrium and the ideal gas law are assumed, the vertically integrated range delay is a function of the surface pressure only (Chelton, 2001). The dry meteorological tropospheric range correction is defined by the following formula:

Dry_Tropo $=-2.277 \cdot P_{\mathrm{atm}}(1+0.0026 \cdot \cos (2 \cdot \mathrm{LAT}))$

where $P_{\text {atm }}$ is the surface atmospheric pressure in mbars, LAT is the latitude, and Dry_Tropo is the dry tropospheric correction in millimeters.

As there is no straightforward way of measuring the nadir surface pressure from altimetry, it is determined from a global atmospheric model. The operational dry tropospheric correction (named DT_ECMWF hereafter) is based on the ECMWF operational analyses, which have a $6 \mathrm{~h}$ time resolution (cf. AVISO, 2011).

\subsubsection{Specific processing for $\mathrm{S} 1$ and $\mathrm{S} 2$ atmospheric tides}

Concerning the dry tropospheric correction, the diurnal (S1) and semidiurnal (S2) atmospheric tides also demand specific processing because they are not well sampled by the $6 \mathrm{~h} \mathrm{ECMWF}$ pressure fields due to Nyquist theory.

The methodology chosen to correct the operational Dry_Tropo from S1 and S2 atmospheric tides, is based on Ponte and Ray (2002) to remove S1 and S2 atmospheric pressure climatology from the ECMWF pressure field, as described in the DAC Sect. 3.1.1. A second step consists of adding correct $\mathrm{S} 1$ and $\mathrm{S} 2$ atmospheric tides from a specific atmospheric tide model (Ray and Ponte, 2003).

\subsubsection{The new dry tropospheric correction derived from ERA-Interim}

The ERA-Interim dry tropospheric correction (DT_ERA) is based on the ERA-Interim atmospheric pressure (mean sea level pressure field), with a $6 \mathrm{~h}$ temporal resolution, and specific S1 and S2 climatologies described in Sect. 3.1.1. The new correction is available for the 1991-2013 period.

\subsection{Method of comparison}

In order to compare the studied corrections and to estimate their impact on the accuracy of altimeter data, the first step consists of interpolating the grids of DAC and DT corrections on the satellites' ground tracks bilinearly in space and time. Differences between ERA-Interim-based corrections and the operational ECMWF corrections can then be investigated along track for each altimeter. The along-track interpolated values also allow computing the altimeter SSH successively using each of the corrections, ERA-based or operational ones. The differences in the sea level contents are analyzed for different time and spatial scales. Notice that even the pressure-derived corrections solely depend on the state of the atmosphere, considering several altimeters allows studying different temporal periods: for example, TP, Jason1 , and Jason-2 are consecutive data sets. Moreover, as TP and ERS ground tracks have different orbit characteristics (cycle, heliosynchronous), using these two types of data allows for consideration of different aliasing problems.

The impact of DAC_ERA and DT_ERA is primarily estimated for short temporal scales (time lags lower than 10 days), which are very significant for these corrections as they contain a large part of their variability (Vinogradova et al., 2007). Moreover, these short temporal scales are indirectly linked with climate scales since high temporal frequency errors increase the formal error estimation of larger temporal scale signals.

The impact of using each of the studied corrections on the SSH performances is estimated by computing the SSH differences between ascending and descending tracks at crossovers 

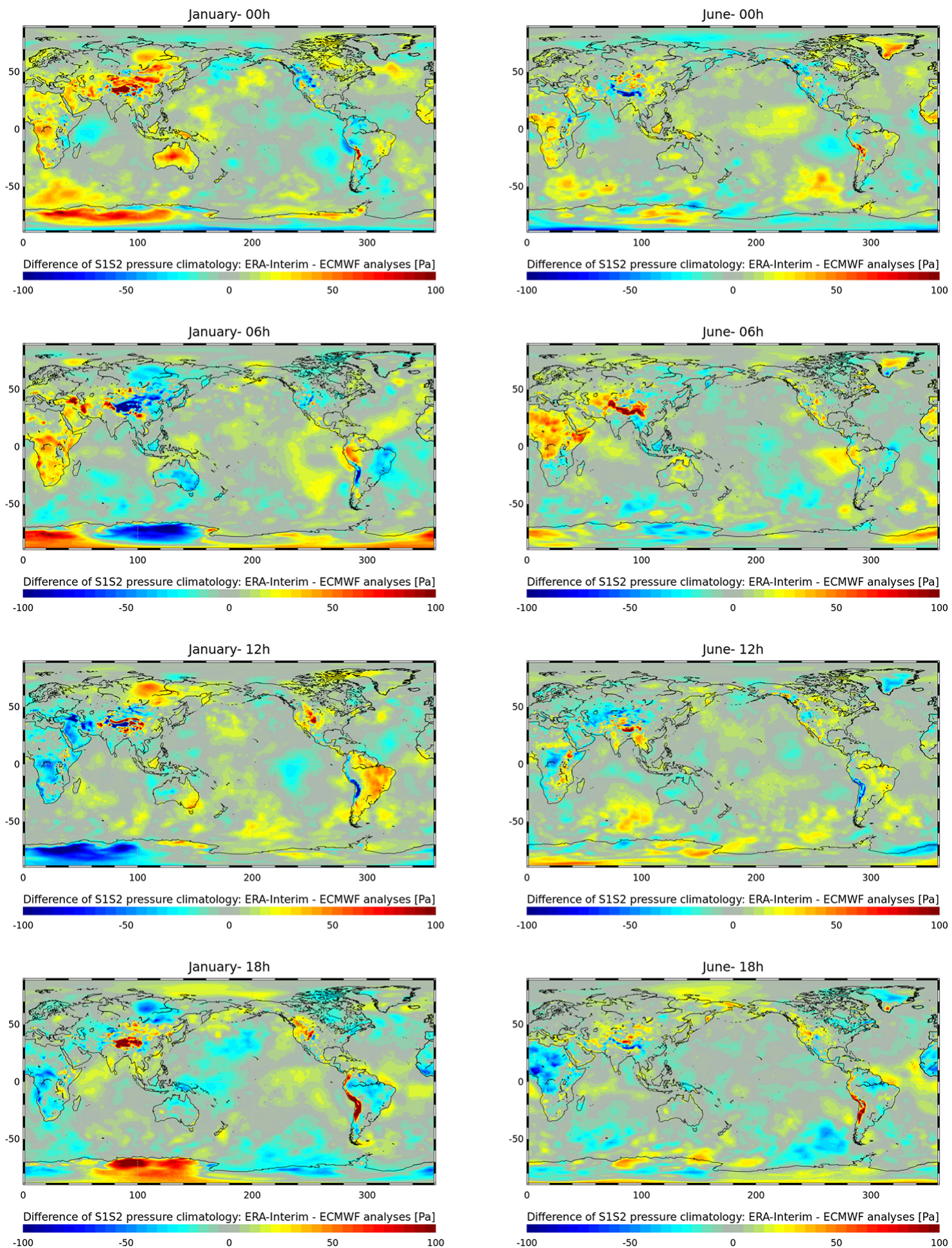

Figure 2. Difference of S1S2 atmospheric pressure climatologies from ERA-Interim and ECMWF analyses, where S1 and S2 represent the diurnal and semidiurnal atmospheric tides, respectively. 

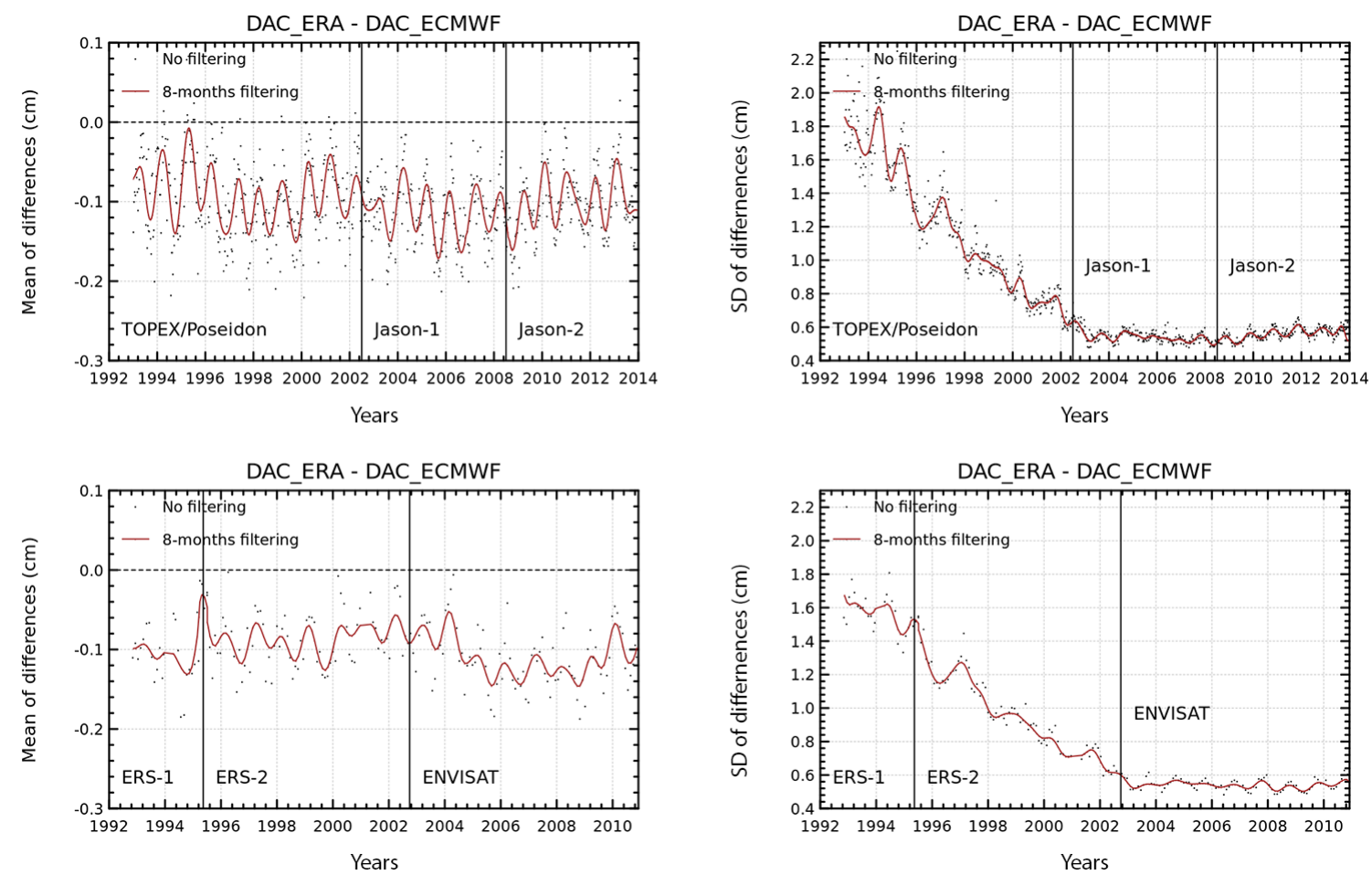

Figure 3. Temporal evolution of the global differences between DAC_ERA and the operational DAC seen by each altimeter mission: TP, Jason-1, and Jason-2 (top), and ERS-1, ERS-2, and Envisat (bottom) (mean and standard deviation in centimeters).

of each altimeter, successively using the studied correction and the reference one. Crossover points with time lags shorter than 10 days within one cycle are selected in order to minimize the contribution of the ocean variability at each crossover location. The DAC is by essence a high-frequency correction as described in Sect. 3.1, with short temporal autocorrelation scales (Lamouroux, 2006; Mourre, 2004), and the DT is directly proportional to pressure field (cf. Sect. 3.2); thus, this diagnostic allows a good estimation of the impact of the DAC and the DT correction on the high-frequency part of the altimeter $\mathrm{SSH}$, focusing on signals with periods below 10 days in the case of this crossover's diagnostics.

The maps of the variance difference of SSH differences at crossover points successively using each altimetric component in the SSH calculation are first computed; they are computed on small boxes of $4^{\circ} \times 4^{\circ}$ and give information on the temporal variance of the SSH differences. The long-term monitoring of SSH is estimated thanks to the calculation of global statistics for each altimeter cycle, all along the time span of each mission, and considering multi-mission concatenated time series as described in Fig. 1; this gives information about the temporal evolution of the spatial variance of the SSH differences. For both diagnostics, the reduction of variance indicates a better internal consistency of sea level between ascending and descending passes within a 10-day window and thus characterizes a better SSH performance. SSH differences at crossovers focus on HF variability and the spatial resolution of this diagnostic is limited due to the localization of crossovers.

To pursue the analysis further to the coast, we consider along-track observations instead of crossovers: the alongtrack SLA statistics are calculated from $1 \mathrm{~Hz}$ altimetric measurements. Although high-frequency signals are aliased in the lower-frequency band following the Nyquist theory application to each altimeter sampling, SLA time series contain the entire ocean variability spectrum. To investigate the impact of the new DAC near the coasts, the differences of SLA variances, computed by successively using both DAC corrections, can be plotted as a function of coastal distances between 0 and $100 \mathrm{~km}$.

The analysis is finally focused on ocean long-term evolution at global and regional scales, which is relevant for climate studies. The global and regional MSL trends are computed for each altimetric mission considered here (from 1992 onwards), applying the MSL calculation method described on AVISO website:

http://www.aviso.altimetry.fr/en/data/products/ ocean-indicators-products/mean-sea-level.html (Ablain et al., 2009). Basically mean grids of SLA are first computed for each cycle of each mission (every $\sim 10$ days); then the global mean of each grid is computed for each cycle to estimate the global MSL slope for each mission. The regional MSL slopes for each mission are then estimated using previous SLA grids for each cycle and each mission 

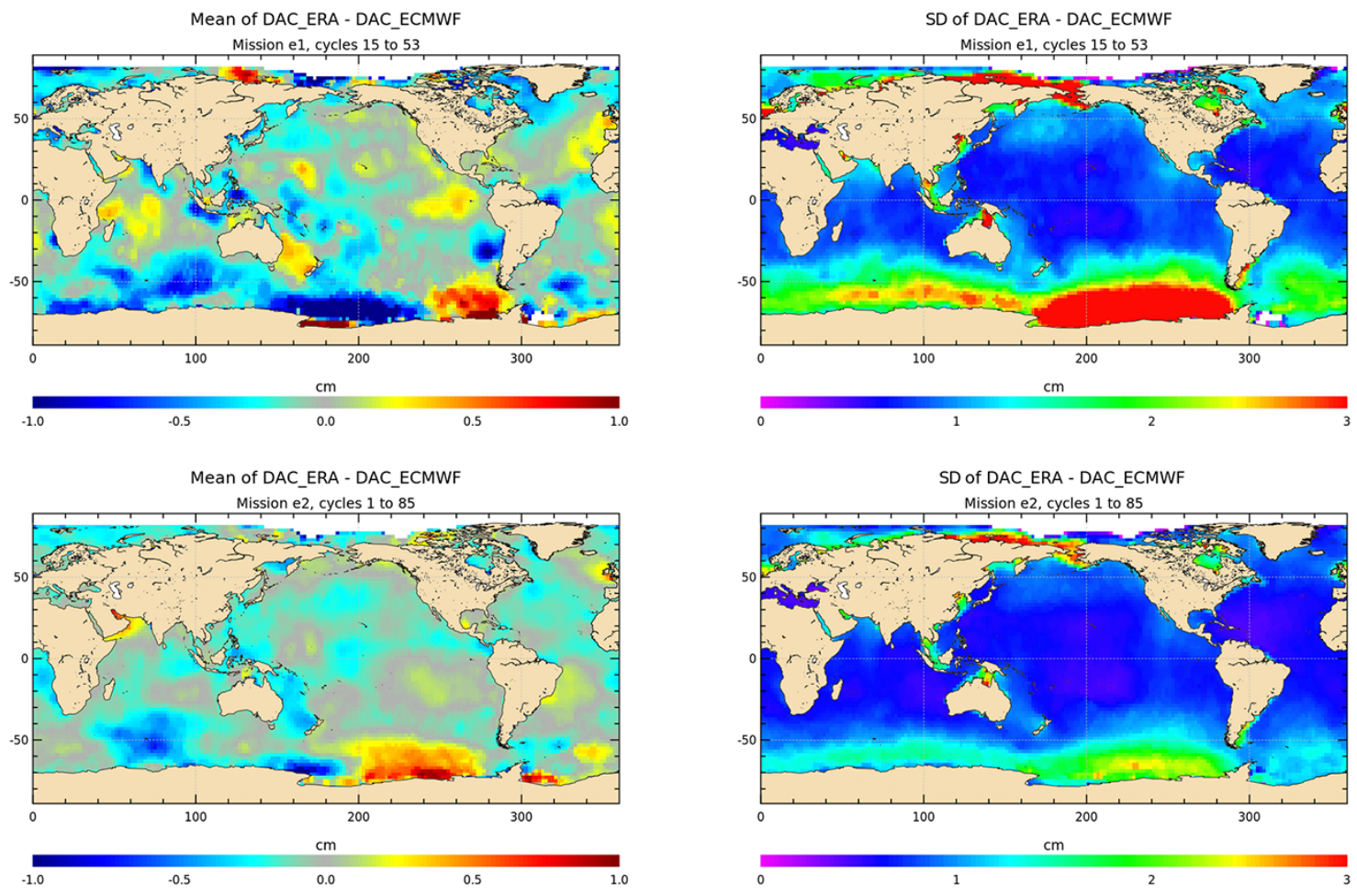

Mean of DAC_ERA - DAC_ECMWF Mission en, cycles 10 to 93
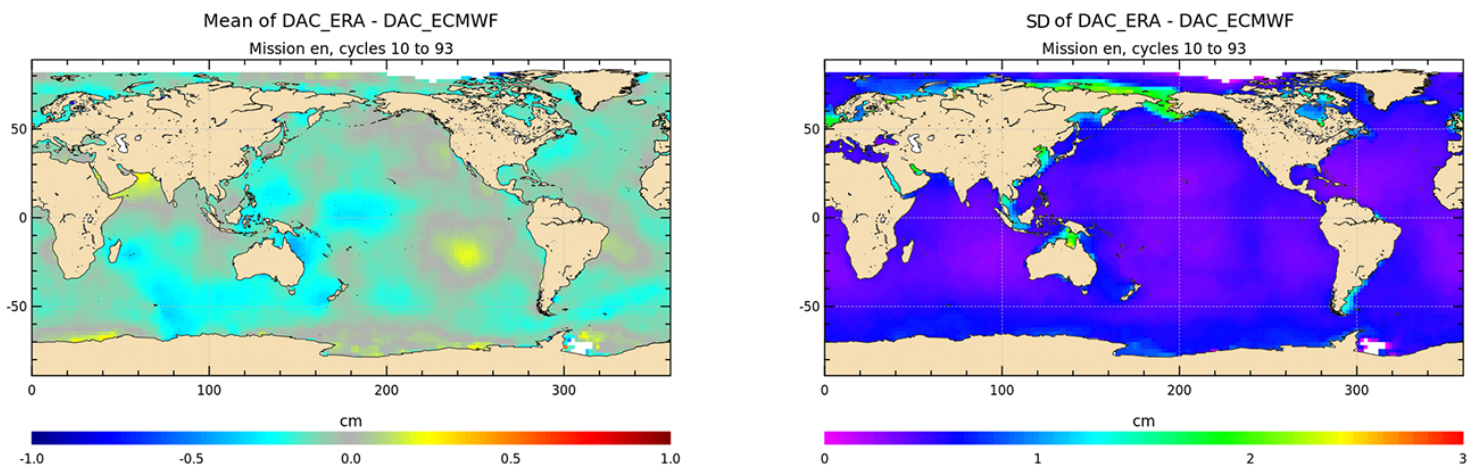

Figure 4. Statistics of differences between DAC_ERA and the operational DAC seen by ERS-1, ERS-2, and Envisat altimeter missions (mean and standard deviation in centimeters).

and a least square method at each grid point. Trends are estimated for each SLA successively using the studied and the reference DAC and DT corrections. Notice that the trends of the altimetric missions can be very different one to the other due to the impact of the mission's timespan on the trend estimation, with a longer timespan allowing a more accurate trend estimation. The error bar of the MSL trends' estimation is about $0.5 \mathrm{~mm} \mathrm{yr}^{-1}$ (Ablain et al., 2015).

\section{Analysis of the differences of atmospheric pressure-derived corrections}

In this section, we analyze the differences between the reference (ECMWF-based) and the studied (ERA-Interim-based) atmospheric pressure-derived corrections, namely DAC and DT, at global and regional scales; a long-term analysis of these differences is also presented for the 20 years of altimetry data available.

\subsection{The dynamic atmospheric correction}

The monitoring of the global differences between DAC_ERA and DAC_ECMWF corrections and also of the map of the differences provide information concerning the impact of the studied correction at the global and regional scales and for different timescales. Figure 3 shows the monitoring of the standard deviation and the mean of the differences between both corrections during a 20 -year period. Figure 4 shows the maps of the differences (mean and standard deviation) for the 

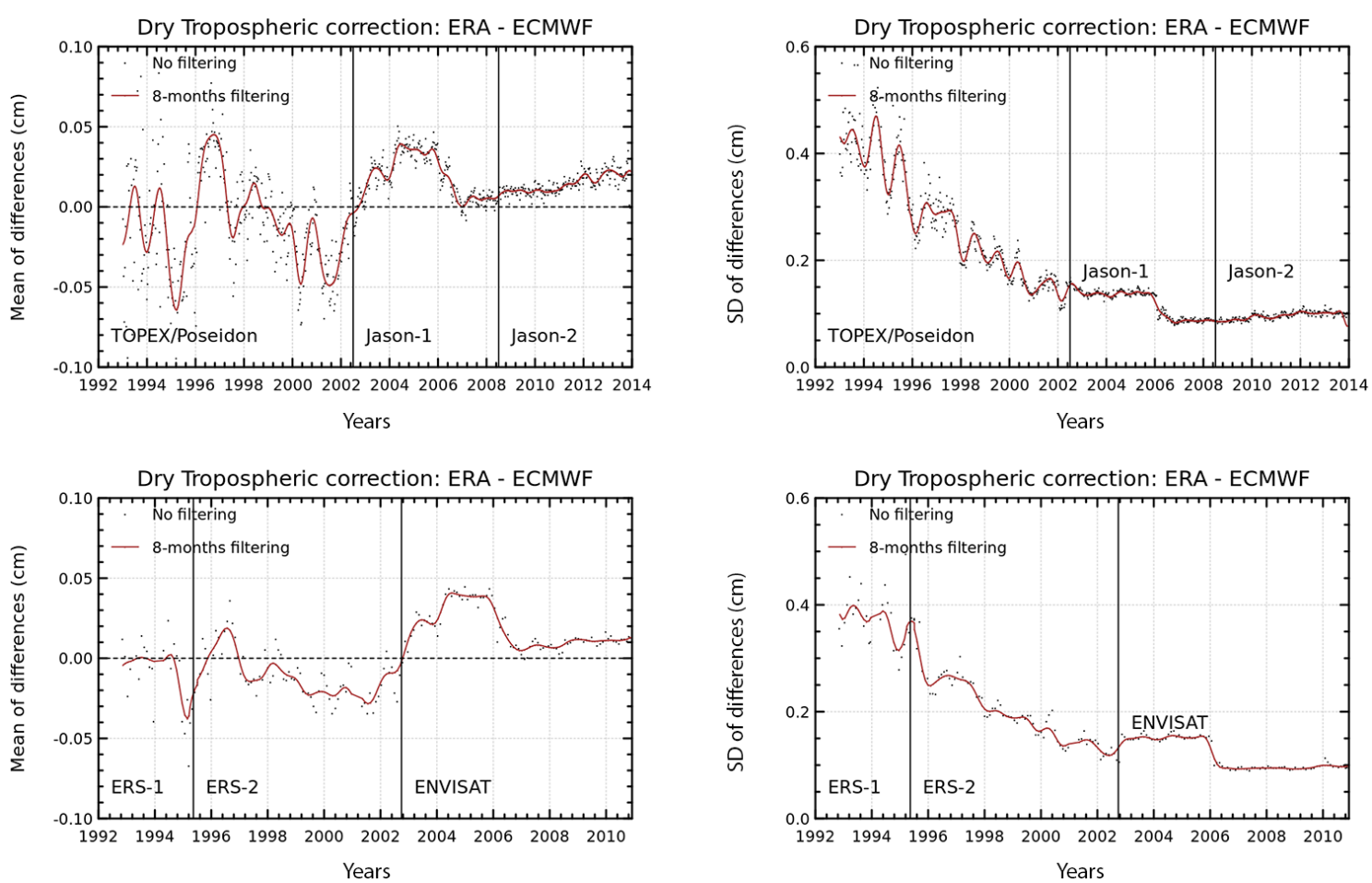

Figure 5. Temporal evolution of the differences between dry tropospheric ERA and the operational dry tropospheric correction seen by each altimeter missions series: TP, J1, J2 time series (top), and ERS-1, ERS-2, and Envisat time series (bottom) (mean and standard deviation in centimeters).

ERS-1, ERS-2, and Envisat missions, which cover the nearly entire altimetric period considered.

The mean difference between both corrections is about $1 \mathrm{~mm}$, with annual variations below a few tenths of a millimeter for all missions. The standard deviation of the differences clearly evolves with time, with strong differences for the first years of altimetry (up to $1.6-1.8 \mathrm{~cm}$ for ERS- 1 and TP) which decrease until the year 2002 and then become stable around $0.5 \mathrm{~cm}$ for Envisat, Jason-1, and Jason-2. A low annual signal is likely explained by the seasonal ice cover's impact.

The maps of the differences also indicate stronger values for old altimeter missions: the mean of differences shows values up to $1 \mathrm{~cm}$ or even more in some large regions mainly located in southern high latitudes for ERS-1, ERS2, and in the Arctic and other ocean regions for ERS-1. As expected from the atmospheric pressure and wind highfrequency variability, the standard deviation of differences shows weak differences in the intertropical area (between latitudes $40^{\circ} \mathrm{S} / 40^{\circ} \mathrm{N}$ ) and strong differences of several centimeters (over $3 \mathrm{~cm}$ ) in southern high latitudes, in the Bering Strait, in the Arctic, and in some shallow water regions. The differences are stronger in the southern Pacific for the three old missions considered and significantly higher for the oldest one, ERS-1.
Concerning more recent missions such as Envisat, mean differences maps show some patterns with small differences below $0.4 \mathrm{~cm}$, and standard deviation maps indicate values below $0.8 \mathrm{~cm}$ on most of the global ocean and up to $1.8-2 \mathrm{~cm}$ in a few shallow water regions. Those results confirm that both atmospheric models considered are very close in recent years, but some differences remain in shallow waters likely explained by the lower resolution of the reanalysis for this period.

\subsection{The dry tropospheric correction}

Figure 5 shows the monitoring of the global standard deviation and mean differences between DT_ERA and DT_ECMWF corrections during a 20-year period. Figure 6 shows the map of the differences between both corrections (mean and standard deviation) for the ERS-1, ERS-2, and Envisat missions.

The mean difference between both corrections is nearly null, with variations lower than a few tenths of a millimeter for all missions. As for the DAC, the standard deviation of the differences is stronger for old missions, with lower values than for the DAC because the DT correction is a smaller amplitude correction: differences reach $0.4 \mathrm{~cm}$ for TP and ERS1 missions, and $0.1 \mathrm{~cm}$ for Jason- 2 mission, one-fourth of the differences observed for DAC. A low annual signal is also visible. We notice a small but sharp lowering of the standard 

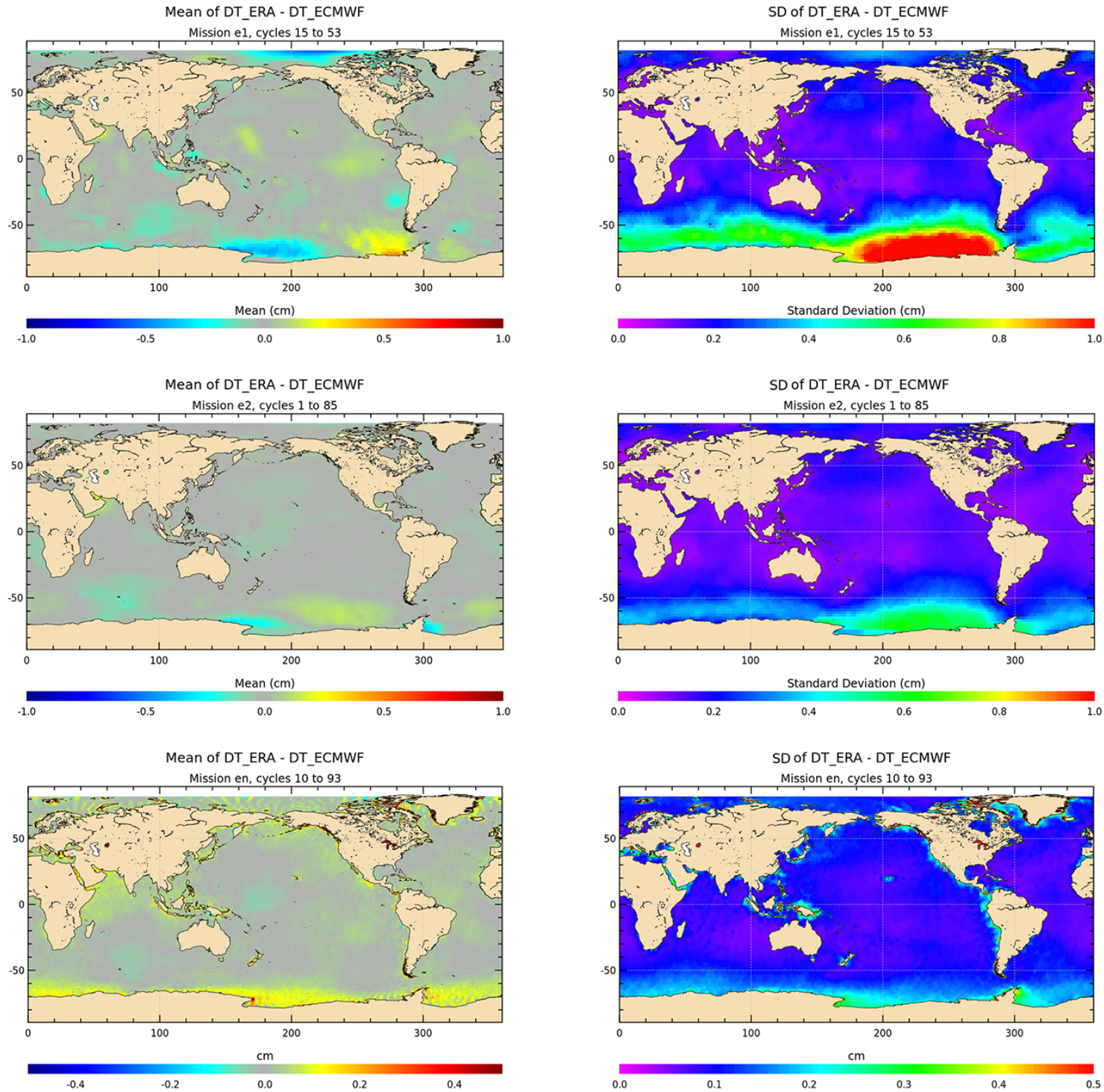

Figure 6. Maps of differences between DT_ERA and the ECMWF operational DT seen by altimeter missions ERS-1, ERS-2, and Envisat (mean and standard deviation in centimeters).
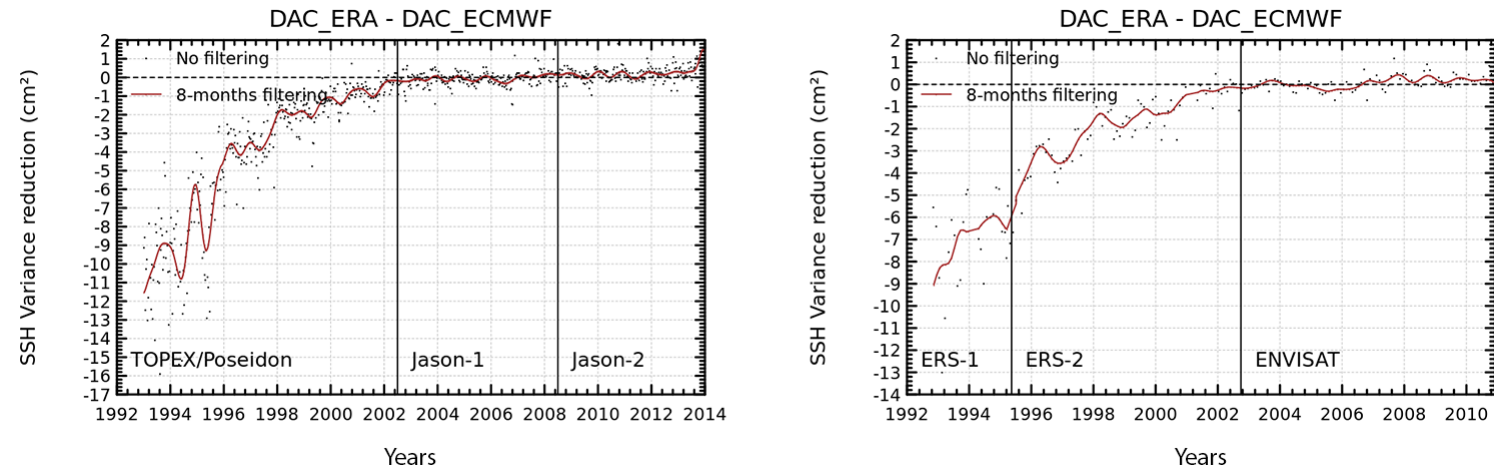

Figure 7. Temporal evolution of SSH variance differences at crossovers successively using the ERA-Interim and reference DAC solutions in the SSH calculation for TOPEX/Jason-1/Jason-2 time series (on the left), and ERS-1/ERS-2/Envisat time series (on the right). 

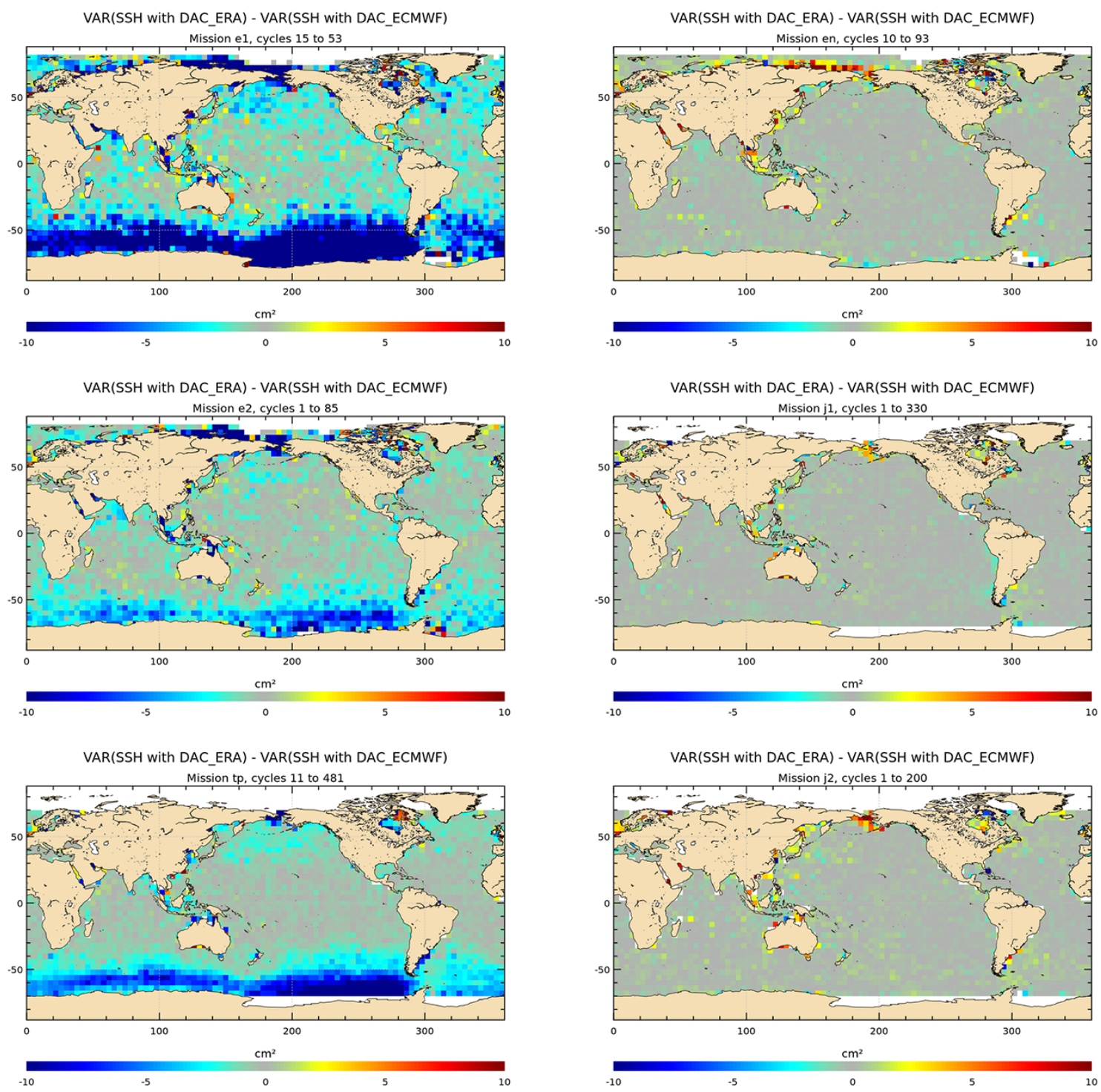

Figure 8. Maps of SSH variance differences at crossovers successively using the ERA-Interim and reference DAC solutions in the SSH calculation for ERS-1, ERS-2, and TP (on the left), and for Envisat, J1, and J2 (on the right) ( $\mathrm{cm}^{2}$ ).

deviation of differences at the beginning of the year 2006; this is likely explained by the resolution change from $\mathrm{N} 256$ to N400 of the ECMWF native grid, and indicates that the DT correction is more affected than DAC by the meteorological model evolutions (cf. ECMWF system evolutions website).

The maps of the differences indicate also stronger values for the old missions - ERS-1 and ERS-2 - than for the more recent Envisat mission; the global mean differences are low for all missions (below $5 \mathrm{~mm}$ ). Following the atmospheric pressure variability pattern, the variability of the difference is stronger in the southern high latitudes and reaches more than $1 \mathrm{~cm}$ for ERS- 1 and up to $0.7 \mathrm{~cm}$ for ERS-2, and only $0.2 \mathrm{~cm}$ for Envisat. We also notice some small-scale oscillations on Envisat maps which are explained by some errors occurring in the operational DT fields based on the Gaussian grid of surface pressure (Gibbs oscillations) used since 2002 (Dibarboure, 2003).

\section{Ocean short temporal scales}

Analyses presented in this section concern high-frequency signals (time differences lower than 10 days). In order to quantify the impact of each correction in the SSH calculation, crossovers and along-track analyses are performed as described in the previous section. We first focus on the impact on the global ocean and then go further into detail with some regional analysis. 


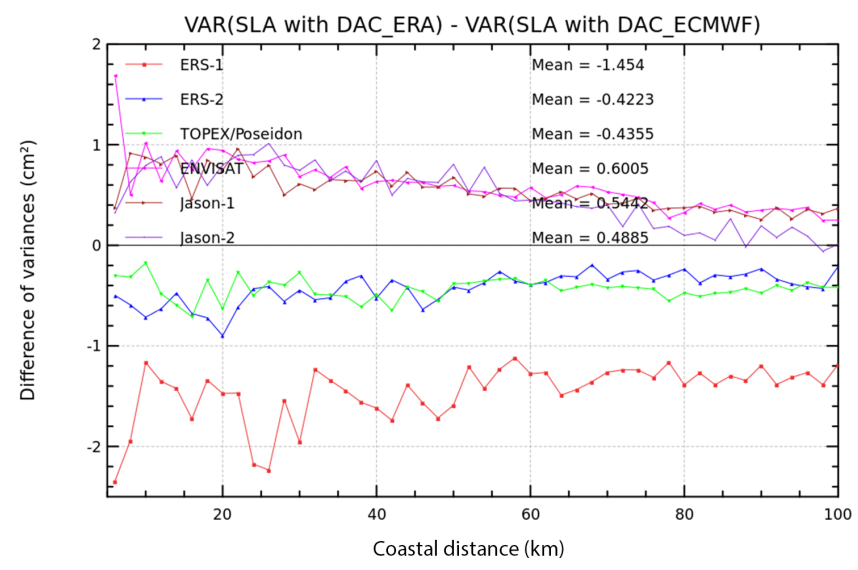

Figure 9. Difference of variance of SLA successively using the ERA-Interim and reference DAC solutions in the SSH calculation, for each altimeter, and as a function of distance to coast.

\subsection{DAC}

The impact of the new DAC_ERA on the SSH performance is first quantified by plotting the temporal evolution of SSH variance differences at crossovers successively using the different DAC in the SSH calculation (cf. Fig. 7), respectively, for the TP/Jason-1/Jason-2 and the ERS-1/ERS-2/Envisat altimeter time series. We note that DAC_ERA strongly reduces the SSH variance compared to the operational DAC on the first years of altimetry: the reduction reaches $5-12 \mathrm{~cm}^{2}$ for the 1992-1996 period, and it corresponds to a mean diminution of the along-track SSH error of $2-3 \mathrm{~cm}$ when using DAC_ERA, which is a very important result. Then this impact diminishes until 2002, but it still remains significant.

Concerning more recent missions (Jason-1, Jason-2, and Envisat), DAC_ERA and DAC_ECMWF have comparable results in terms of crossover variance reduction: differences remain between $\pm 1 \mathrm{~cm}^{2}$ on average during 20022014. DAC_ERA tends to slightly raise the variance compared to ECMWF operational correction only from 2006 and onwards. The very close results of DAC_ERA and DAC_ECMWF in the recent altimeter period are remarkable and not expected since the operational ECMWF model has benefited from significant improvements over time. Evolution of ECMWF operational data set is linked to improved modeling, resolution, and data assimilation process: operational database has a $0.5^{\circ}$ resolution until 2006 , to be compared to the $0.7^{\circ}$ of ERA-Interim; then the operational model resolution changed to $\mathrm{N} 400\left(\sim 0.2^{\circ}\right)$ in January 2006 , and to N640 in 2010 (cf. ECMWF evolutions website). Global ocean results suggest that modeling and data assimilation improvements contained in ERA-Interim have a very important impact and overwhelm the lower resolution issue of ERAInterim for most of the studied period, even until 2006. Only the last versions of the ECMWF operational model tend to slightly improve DAC_ECMWF compared to DAC_ERA in the recent years.

To investigate regional patterns, the maps of SSH variance difference at crossovers successively using the DAC_ERA and the reference DAC, for each altimeter mission are plotted in Fig. 8: old missions (ERS-1, ERS-2, and TP) and the recent ones (Jason-1, Jason-2, and Envisat). Regionally, the improvement of sea level estimation is very significant using the DAC solutions derived from ERA-Interim for all old missions tested (ERS-1, ERS-2, and TP): DAC_ERA allows the reduction of the residual variance at crossovers by more than $10 \mathrm{~cm}^{2}$ in the Southern Ocean where the high-frequency dynamic response of the ocean to atmospheric forcing is very important (Webb and de Cuevas 2002a, b, 2003; Carrere, 2003; Vinogradova and Ponte, 2007). The reduction is also significant in many shallow water regions like the Bering Strait, the Hudson Bay, the Patagonian Shelf, north Australia, the Yellow Sea, and the Arctic Ocean. In all those regions, DAC_ERA correction allows diminishing the along-track error by more than $3 \mathrm{~cm}$, compared to DAC_ECMWF, which is very significant. Those results show that the ERA-Interim reanalysis is much more accurate than the operational ECMWF model, which is used to compute the reference DAC, in the first decade of altimetry.

If considering the second decade of altimetry (Envisat, Jason-1, and Jason-2), both models of DAC have a similar impact in deep ocean regions but using DAC_ERA raises the SSH crossovers variance in some shallow water regions like the Bering Strait, the Arctic Ocean, the South China Sea, the Patagonian Shelf, or around Australia. This local variance increase can be explained by the better resolution of the operational forcing in the recent years, which is an asset to solving the short spatial scales characteristic of shallow coastal areas; this increase is stronger for Envisat and Jason-2 which are the most recent altimeters studied here. The impact of DAC_ERA as a function of distance to coast for the global ocean is shown in Fig. 9, confirming previous results: DAC_ERA allows reducing the SLA variance near the coasts for old altimeter missions while it tends to raise it slightly when considering more recent missions.

\subsection{Dry tropospheric correction}

The impact of the new DT_ERA on the SSH performance is evaluated thanks to the estimation of the temporal evolution of SSH variance differences at crossovers successively using different DT corrections in the SSH calculation as plotted in Fig. 10. As for DAC_ERA, DT_ERA correction strongly reduces the variance compared to DT_ECMWF for the first years of altimetry: reduction reaches $2-5 \mathrm{~cm}^{2}$ for the $1992-$ 1996 period, which corresponds to a diminution of the alongtrack SSH error by 1-2 cm. Even the impact of DT_ERA is weaker than DAC_ ERA's impact due to the smaller amplitude of the correction itself; the impact of DT_ERA is very significant in the first decade of altimetry. Afterwards, 

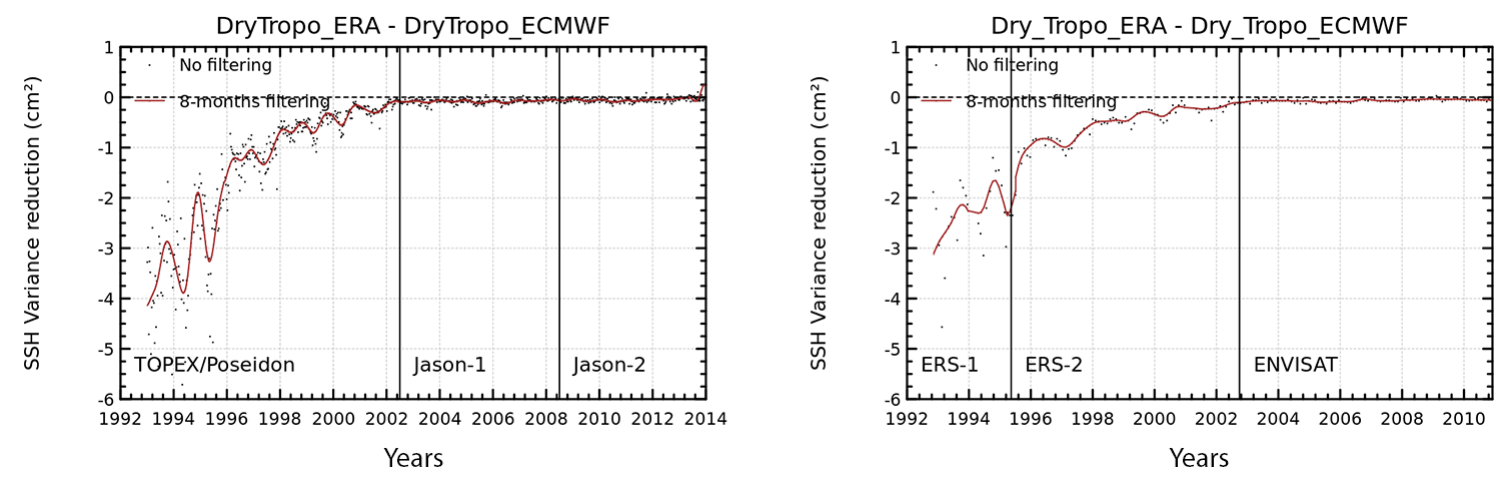

Figure 10. Temporal evolution of SSH variance differences at crossovers successively using the ERA-Interim and ECMWF operational DT corrections in the SSH calculation for TOPEX/Jason-1/Jason-2 series (on the left), and ERS-1/ERS-2/Envisat (on the right).
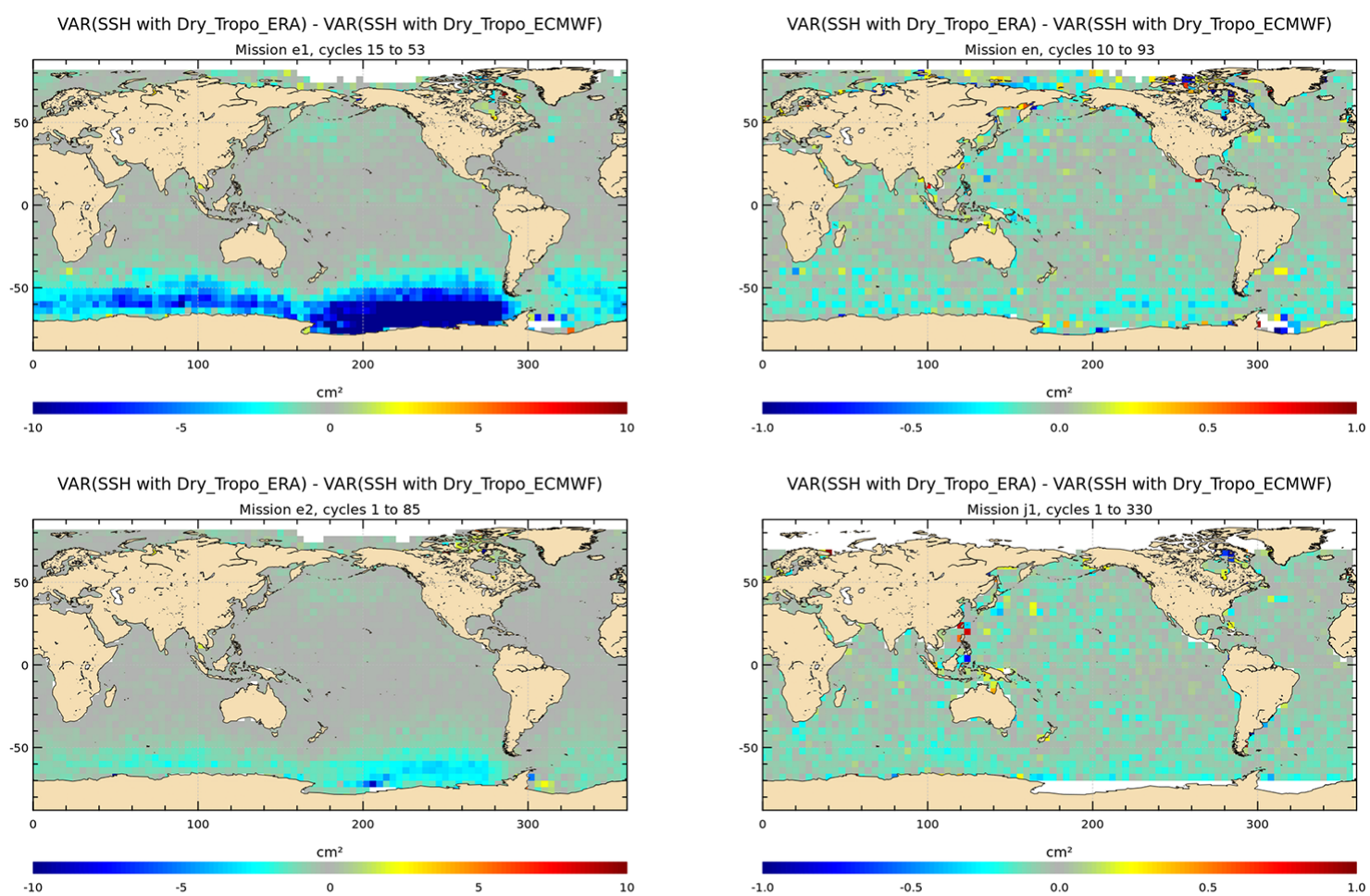

VAR(SSH with Dry_Tropo_ERA) - VAR(SSH with Dry_Tropo_ECMWF)
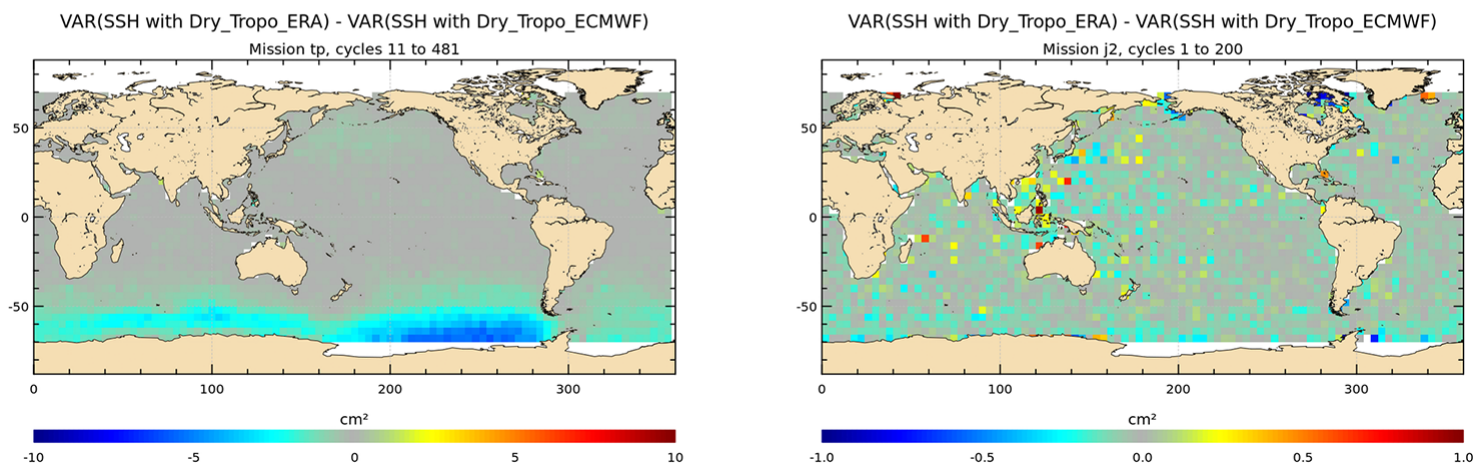

Figure 11. Maps of SSH variance differences at crossovers successively using the ERA-Interim and ECMWF operational DT corrections in the SSH calculation for ERS-1, ERS-2, and TOPEX (on the left), and for Envisat, Jason-1, and Jason-2 (on the right) (cm²). 

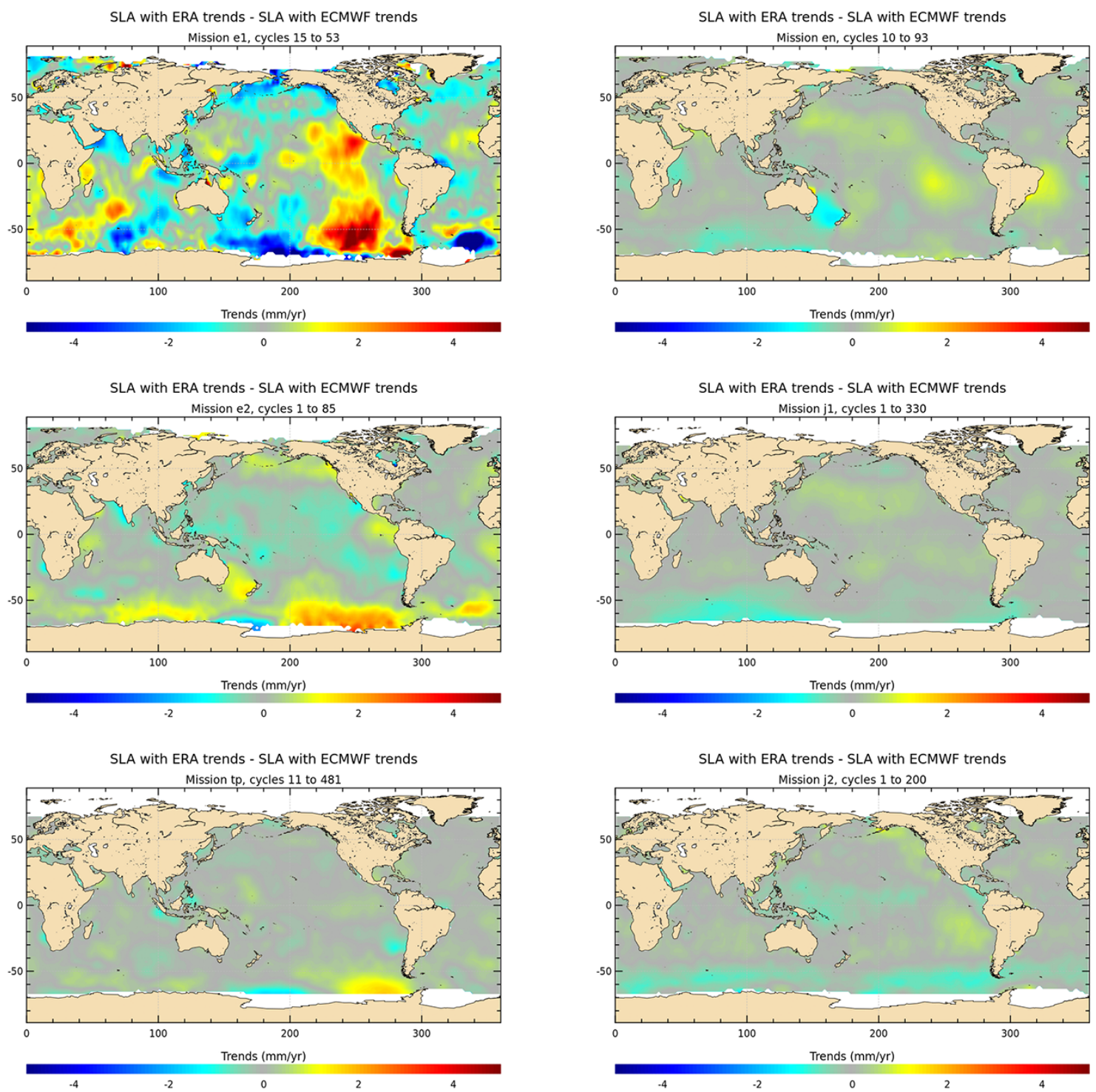

Figure 12. Maps of MSL trend differences successively using the DAC derived from ERA-Interim and from ECMWF operational pressures fields (reference) for ERS-1, ERS-2, and TOPEX (on the left), for Envisat, Jason-1, and Jason-2 (on the right) $\left(\mathrm{mm} \mathrm{yr}^{-1}\right.$ ).

Table 2. Impact of ERA-Interim-based corrections (DAC_ERA and DT_ERA) on global MSL trends and the least square root estimation error (LSR) $\left(\mathrm{mm} \mathrm{yr}^{-1}\right)$.

\begin{tabular}{lcrr}
\hline Altimeter mission & $\begin{array}{c}\text { MSL trend using ECMWF } \\
\text { corrections (reference) } \\
\text { (LSR }\end{array}$ & $\begin{array}{r}\text { Difference of MSL trend: } \\
\text { ECMWF - DAC_ERA }\end{array}$ & $\begin{array}{r}\text { Difference of MSL trend: } \\
\text { ECMWF - DT_ERA }\end{array}$ \\
\hline ERS-1 & $6.34 \pm 0.62$ & 0.07 & 0.01 \\
ERS-2 & $2.66 \pm 0.15$ & 0.01 & -0.02 \\
TP & $3.12 \pm 0.03$ & -0.02 & 0.01 \\
EN & $2.28 \pm 0.18$ & -0.04 & -0.03 \\
J1 & $2.55 \pm 0.07$ & 0 & -0.02 \\
J2 & $3.18 \pm 0.15$ & 0.07 & 0.07 \\
\hline
\end{tabular}




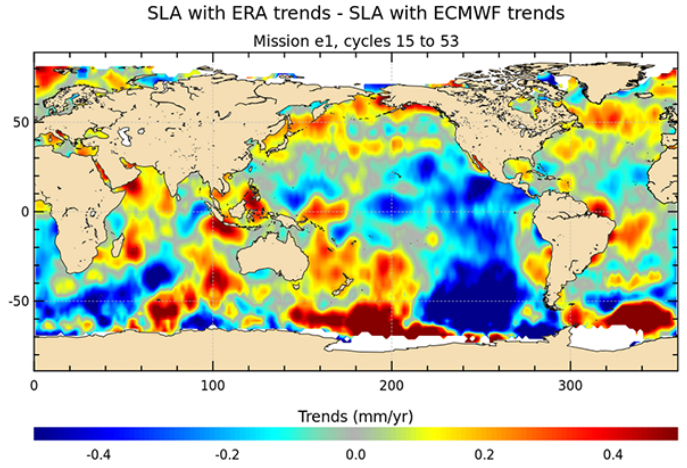

SLA with ERA trends - SLA with ECMWF trends
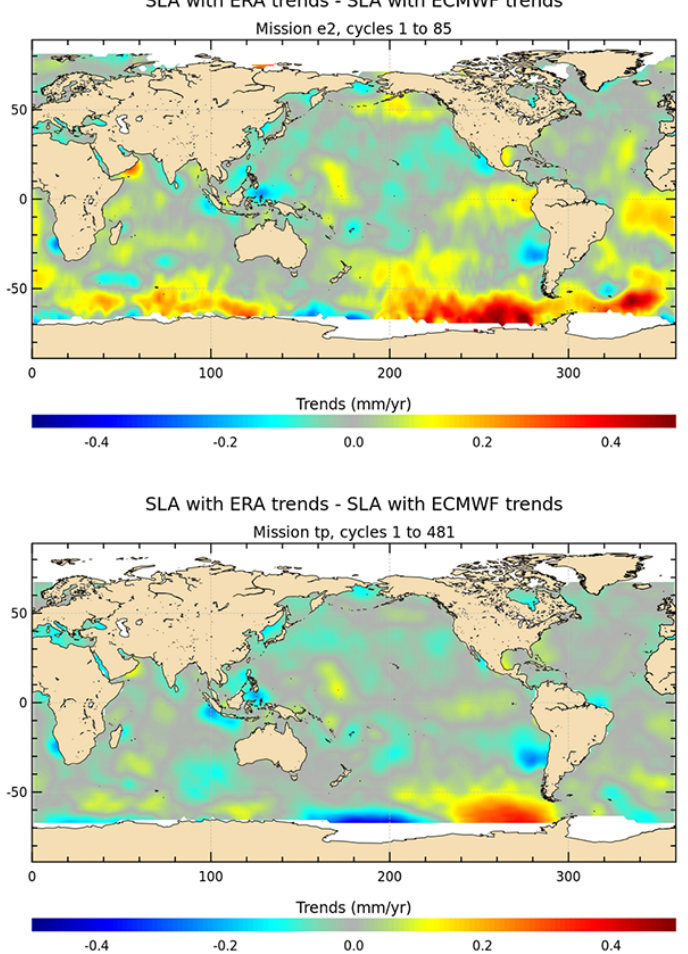

SLA with ERA trends - SLA with ECMWF trends

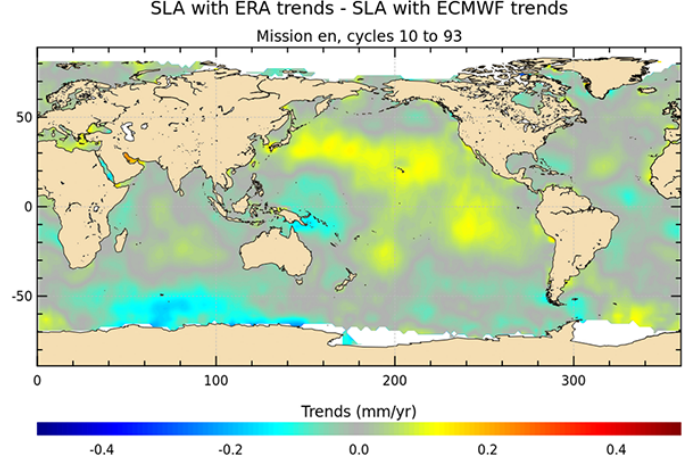

SLA with ERA trends - SLA with ECMWF trends

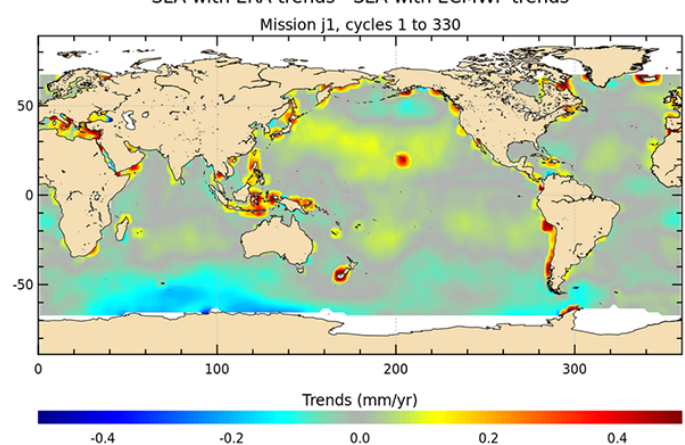

SLA with ERA trends - SLA with ECMWF trends Mission j2, cycles 1 to 200

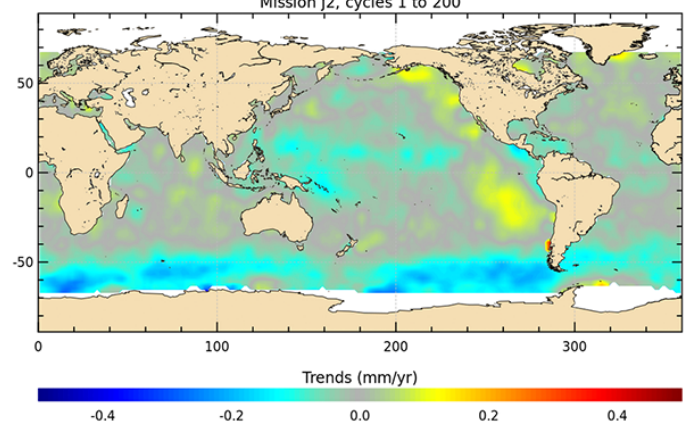

Figure 13. Maps of MSL trend differences successively using the DT correction derived from ERA-Interim and from ECMWF operational pressures fields (reference) for ERS-1, ERS-2, and TOPEX (on the left), for Envisat, Jason-1, and Jason-2 (on the right) (mm yr ${ }^{-1}$ ).

this impact diminishes until it gives similar results to the operational DT_ECMWF for the 2002-2013 period. It is worth noting that the SSH variance reduction obtained with DT_ERA remains negative for the entire period, showing a slight improvement in the last decade; this result was not expected.

The maps of SSH variance difference at crossovers successively using DT_ERA and DT_ECMWF (cf. Fig. 11) give information about the regional patterns of this improvement for each altimeter. The maximum variance reduction is localized at high latitudes, where the variability of atmospheric pressure is at its maximum. The regional improvement of sea level estimation is very significant using the DT_ERA solution for all old missions, ERS-1, ERS-2, and TP: the variance gain is the strongest for ERS-1 and reaches more than $10 \mathrm{~cm}^{2}$ in the high latitudes. For ERS-2 and TP, the variance gain is a bit smaller but remains significant in the Southern Ocean.

If considering more recent missions (Envisat, Jason-1, and Jason-2), we notice that DT_ERA still allows reduction of the SSH variance on the global ocean, even in most recent years (Jason-2). This unexpected result is worth underlining, as the operational ECMWF pressure field benefits from a better resolution than ERA-Interim for this period which should improve the quality of the DT_ECMWF correction. However, these results suggest that the impact of the delayed-time assimilation window used for ERA-Interim reanalysis (Dee et al., 2011) is more important than the spatial resolution for the quality of the DT correction. 


\section{Ocean long-term climate signals}

The impact of using the new ERA-Interim-derived atmospheric corrections (DAC_ERA and DT_ERA) instead of the operational correction is analyzed in terms of long-term trends of the altimeter SLA. Operational ECMWF analyses are known to contain drifts due to the evolution of the operational model upon time (change of computational methods and in the data assimilation system; Thorne and Vose, 2010), which can impact the MSL trend estimations (Ablain et al., 2009). As meteorological reanalyses ensure greater homogeneity of the database over time, they are thus more suitable for long-term signal estimations as already discussed by Ablain et al. (2009) and Legeais et al. (2014). Moreover, reduced high-frequency errors, thanks to the better quality of the reanalysis as described in previous sections, will decrease the formal error estimation of the long-term signals such as the MSL trend. MSL trends at global and regional scales are investigated as described in Sect. 2.3. Particularly as the difference between ECMWF and ERA-Interim-based corrections shows large spatial patterns of strong variability, the regional MSL trends may be significantly affected by the use of the pressure-derived corrections based on ERA-Interim.

Global analysis shows that the new ERA-Interim-based solutions have a very small impact on the estimation of the global MSL trends of different altimeter missions considered in the study: Table 2 indicates that differences of trends are smaller than $0.07 \mathrm{~mm} \mathrm{yr}^{-1}$, which is 1 order of magnitude lower than the global MSL trend uncertainty: $0.5 \mathrm{~mm} \mathrm{yr}^{-1}$ (Ablain et al., 2015). Even meteorological models can have instabilities or jumps due to model evolutions, this weak impact on global trends could be expected as the mean pressure is removed to perform the IB and to force the barotropic model, and the DAC is computed with an instantaneous zero mean. As seen in Fig. 5, the DT is more affected by meteorological model evolutions as it depends on the pressure field, but results indicate that the impact on MSL trend is negligible at a global scale.

Notice that the trend differences observed between each mission are not significant, as they are mostly explained by the different lengths of the temporal series available.

The impact of using ERA-Interim-based corrections on the regional MSL trends' estimation is analyzed in terms of spatial distribution of the MSL trends for each mission considered in the study (cf. Figs. 12 and 13). Although no impact is detected on the global MSL trend, using DAC_ERA correction instead of DAC_ECMWF has a significant impact on the estimation of regional trends. Considerable trend differences are displayed for the oldest missions; differences are located nearly everywhere on the global ocean for ERS-1 $\left( \pm 7 \mathrm{~mm} \mathrm{yr}^{-1}\right)$ and are likely explained by the strong differences between DAC_ERA and DAC_ECMWF for this period, but also by the short time span of the ERS-1 temporal series, which makes the MSL trends' estimation less accurate and less stable. MSL trends differences are mostly located in the southern high latitudes for ERS-2 $\left( \pm 2.5 \mathrm{~mm} \mathrm{yr}^{-1}\right)$ and TP $\left( \pm 1.5 \mathrm{~mm} \mathrm{yr}^{-1}\right)$, which correspond to the regions where the differences between the DAC solutions themselves are the greatest and also where the SSH variance reduction is strong. Concerning more recent missions, the impact of DAC_ERA on regional MSL trends' estimation is smaller than for old missions, but it is still not negligible: differences locally reach 1-1.5 $\mathrm{mm} \mathrm{yr}^{-1}$ for Envisat, Jason-1, and Jason-2. The impact of DAC_ERA on the estimation of regional trends is likely explained by the fact that DAC_ERA strongly reduces the high-frequency variability locally as discussed in previous sections, and thus the formal error of the least square adjustment of the MSL trends is also reduced; this impact is all the more important because the regional trends are more affected by the oceanic variability and annual/semiannual signals than global trends.

Using the new DT_ERA correction instead of the DT_ECMWF has a weak impact on the regional MSL trends, as seen in Fig. 13: differences are lower than $0.3 \mathrm{~mm} \mathrm{yr}^{-1}$ on the global ocean for most of missions. Differences are stronger for the ERS-1 mission, reaching $0.5 \mathrm{~mm} \mathrm{yr}^{-1}$ or even a bit more on nearly the entire ocean, but these stronger values are likely mainly due to the shorter time series available for this mission.

The different diagnostics presented here point out some differences for long-term regional trends' estimation, when using the ERA-based corrections instead of operational corrections, but they do not demonstrate which trend is the most realistic. Comparisons with in situ measurements (Valladeau et al., 2012) as well as tide gauges or temperature and salinity profiles do not allow obtaining relevant results mainly due to the errors of the methods. However, as the DAC_ERA and DT_ERA induce strong improvements when considering short temporal scales (cf. Sect. 4), and because these high frequencies are related to lower frequencies through the aliasing phenomena and contribute to the formal error estimation of longer timescale signals, we can assume that the DAC_ERA and the DT_ERA corrections have a positive impact on regional MSL trends' estimation.

\section{Discussion and conclusions}

New DAC and DT corrections derived from the ERA-Interim reanalysis have been computed for the entire altimetric period. These corrections have been extensively compared to the operational DAC and DT solutions using long time series of six altimeter missions: ERS-1, ERS-2, TP, Envisat, Jason1 , and Jason-2.

Concerning short temporal scales, the improvement of sea level estimations using ERA-based corrections is at its maximum in the first decade of altimetry due to the lower quality of operational ECMWF analysis during this period. The impact is more important at high latitudes where the atmospheric forcing is more energetic, and DAC_ERA also shows 
a significant improvement in shallow waters where the ocean has a strong dynamic response to atmospheric forcing at high frequencies. Using the new DAC_ERA correction induces a diminution of the along-track SSH error of about $1-2.4 \mathrm{~cm}$ globally and even more than $3 \mathrm{~cm}$ at high latitudes and in shallow waters. Although the DT correction has a lower variability compared to the DAC, using the new DT_ERA allows reduction of the along-track SSH error by $1-2 \mathrm{~cm}$ on the global ocean and by more than $3 \mathrm{~cm}$ at high latitudes.

Unexpectedly in the three recent missions studied (Envisat, Jason-1, and Jason-2), ERA-based corrections show similar performances to the operational corrections although the meteorological reanalysis has a larger spatial resolution than the ECMWF operational analyses. Moreover, DT_ ERA remains better than DT_ECMWF on the global ocean even in the most recent mission, Jason-2. DAC_ERA and DAC_ECMWF have comparable results in the deep ocean, but DAC_ERA tends to raise the residual crossovers variance in some shallow water regions, where the finer resolution of operational forcing seems more appropriated to solve the small spatial scales characteristic of shallow and coastal ocean dynamic.

Concerning long temporal scales relative to climate studies, the present analysis shows that the ERA-based corrections do not have a significant impact on the global MSL trends. Using DT_ERA does not impact the regional MSL trends either. Using DAC_ERA has a strong effect on longterm regional trends' estimation, with trend differences of several millimeters per year locally.

As the DAC_ERA induces a strong improvement when considering short temporal scales, and because these high frequencies are related to lower frequencies through the aliasing phenomena and contribute to the formal error of the MSL trends' estimation, we can assume that the DAC_ERA has a positive impact on regional MSL trends' estimation.

The results presented here allow recommending the use of DAC_ ERA in the first altimetry decade for ERS-1, ERS-2, and TP missions. For more recent missions, DAC_ERA can also be used at least for long-term signals' estimation to get rid of any discontinuity between both DAC corrections, but at the cost of a slightly raised variance in some shallow water regions. Indeed, if using a combination of DAC_ERA and operational DAC, the continuity between both DAC solutions at regional scales will need to be checked at least for longterm studies.

The dry tropospheric correction derived from ERAInterim pressure field is also of great interest for all applications, and this correction can be used for all altimeter missions even the most recent one studied here, Jason- 2 .

Given the results of the present study, the DAC_ERA and the DT_ERA time series are still being completed in delayed time with a few months' delay. These ERA-based corrections are used in several projects and products like REAPER (2014), CCI-phase-2 project (Ablain et al., 2015), SALP (SSALTO/DUACS, 2015), FES2012 and FES2014 tidal models (Carrere et al., 2012, 2014), and the Jason-1 reprocessing project (Jason-1 products handbook, 2015).

As the ERA-Interim meteorological product has a coarse spatial resolution compared to the operational database in recent years, a perspective of this work will be to test a new atmospheric climatology with a finer spatial grid; this would likely help improving the results presented here in shallow waters and also in the southern deep ocean regions where the ocean response to meteorological forcing is enhanced for topography patterns.

\section{Data availability}

The altimeter AVISO SSALTO/DUACS real-time sea surface height measurements are available at http://www.aviso.altimetry.fr/en/data/products/ sea-surface-height-products/global.html. The climateoriented altimeter sea level anomalies from the ESA climate change initiative project are accessible by request at info-sealevel@esa-sealevel-cci.org and details are provided at http://www.esa-sealevel-cci.org.

Acknowledgements. This work has been performed within the framework of the ESA Climate Change Initiative (CCI) and the SALP (CNES) projects. We thank Paul Poli from ECMWF for the elements of discussion he gave us on the ERA-Interim reanalysis, and Lionel Zawadzki from CLS for his help on the processings.

Edited by: A. Sterl

\section{References}

Ablain, M., Cazenave, A., Valladeau, G., and Guinehut, S.: A new assessment of the error budget of global mean sea level rate estimated by satellite altimetry over 1993-2008, Ocean Sci., 5, 193201, doi:10.5194/os-5-193-2009, 2009.

Ablain, M., Cazenave, A., Larnicol, G., Balmaseda, M., Cipollini, P., Faugère, Y., Fernandes, M. J., Henry, O., Johannessen, J. A., Knudsen, P., Andersen, O., Legeais, J., Meyssignac, B., Picot, N., Roca, M., Rudenko, S., Scharffenberg, M. G., Stammer, D., Timms, G., and Benveniste, J.: Improved sea level record over the satellite altimetry era (1993-2010) from the Climate Change Initiative project, Ocean Sci., 11, 67-82, doi:10.5194/os-11-672015, 2015.

AVISO: OSTM/Jason-2 products handbook, SALP-MU-M-OP15815-CN, Edn. 1.8, http://www.aviso.oceanobs.com/fileadmin/ documents/data/tools/hdbk_j2.pdf (last access: 13 May 2015), 2011.

Carrere, L.: Etude et modélisation de la réponse haute fréquence de l'océan global aux forçages météorologiques, Toulouse, université Toulouse III - Paul Sabatier, 2003.

Carrere, L.: Rapport d'étude CNES/CLS, reference CLS-DOS-NT05-007, 2005.

Carrere, L. and Lyard, F.: Modelling the barotropic response of the global ocean to atmospheric wind and pressure forcing - 
comparisons with observations, Geophys. Res. Lett., 30, 1275, doi:10.1029/2002GL016473, 2003.

Carrere, L., Lefèvre, F., Briol, F., Dorandeu, J., Roblou, L, Jeansou, E., Jan, G., and Lyard, F.: New improvements on the Dynamic Atmospheric Corrections, OSTST, Tides/HF Aliases splinter session, Hobart, Tasmania, 2007.

Carrere, L., Faugère, Y., Dibarboure, D., Bronner, E., and Ponte, R.: Improving the Dynamic Atmospheric Correction for altimetry - impact of 3-hours meteorological fields, OSTST poster presentation, http://www.aviso.altimetry.fr/fr/coin-utilisateur/ equipes-scientifiques/ostst-swt-science-team.html (last access: 23 June 2016), 2010.

Carrere, L., Lyard, F., Cancet, M., Guillot, A., Faugère, Y., and Roblou, L.: FES 2012: a new global tidal model taking advantage of nearly 20 years of altimetry, 20 years of progress in radar altimetry symposium, Venice, 2012.

Carrere, L., Lyard, F., Cancet, M., Guillot, A., Faugère, Y., and Picot, N.: FES 2014: a new tidal model on global ocean, OSTST, Tides/HF session, Constance, 2014.

Cazenave, A., Dieng, H., Meyssignac, B., von Schuckmann, K., Decharme, B., and Berthier, E., The rate of sea level rise, Nature Climate Change, 4, 358-361, doi:10.1038/NCLIMATE2159, 2014.

Chelton, D. B., Ries, J. C., Haines, B. J., Fu, L. L., and Callahan, P. S.: Satellite Altimetry, Satellite Altimetry and Earth Sciences, edited by: Fu, L. L. and Cazenave, A., 1-131, 2001.

Couhert, A., Cerri, L., Legeais, J.-F., Ablain, M., Zelensky, N., Haines, B., Lemoine, F., Bertiger, W., Desai, S., and Otten, M.: Towards the $1 \mathrm{~mm} / \mathrm{y}$ Stability of the Radial Orbit Error at Regional Scales, Adv. Space Res., 55, 2-23, doi:10.1016/j.asr.2014.06.041, 2014.

Dee, D. P., Uppala, S. M., Simmons, A. J., Berrisford, P., Poli, P., Kobayashi, S., Andrae, U., Balmaseda, M. A., Balsamo, G., Bauer, P., Bechtold, P., Beljaars, A. C. M., van de Berg, L., Bidlot, J., Bormann, N., Delsol, C., Dragani, R., Fuentes, M., Geer, A. J., Haimberger, L., Healy, S. B., Hersbach, H., Hólm, E. V., Isaksen, L., Kållberg, P., Köhler, M., Matricardi, M., McNally, A. P., Monge-Sanz, B. M., Morcrette, J.-J., Park, B.-K., Peubey, C., de Rosnay, P., Tavolato, C., Thépaut, J.-N., and Vitart, F.: The ERA-Interim reanalysis: configuration and performance of the data assimilation system., Q. J. Roy. Meteor. Soc., 137, 553-597, doi:10.1002/qj.828, 2011.

Dibarboure, G.: Comparaison des Corrections Météo Gaussiennes et Cartésiennes utilisées dans SSALTO/DUACS, report CLS/CNES, CLS-DOS-NT-03-915, 2003.

ECMWF: system evolutions: http://www.ecmwf.int/en/forecasts/ documentation-and-support/changes-ecmwf-model, last access: March 2016.

Greenberg, D., Dupont, F., Lyard, F., Lynch, D., and Werner, F.: Resolution issues in numerical models of oceanic and coastal circulation, Cont. Shelf Res., 27, 1317-1343, 2007.

Hernandez, F. and Schaeffer, P.: The CLS01 Mean Sea Surface: A validation with the GSFC00.1 surface, CLS report, 2001.

Jason-1 products handbook: http://www.aviso.altimetry.fr/ fileadmin/documents/data/tools/hdbk_j1_gdr.pdf (last access: 4 April 2016), 2015.

Lamouroux, J.: Erreur de prévision d'un modèle océanique barotrope du Golfe de Gascogne en réponse aux incertitudes sur les forçages atmosphériques. Caractérisation et utilisation dans un schéma d'assimilation de données à ordre réduit, $\mathrm{PhD}$, University Paul Sabatier, Toulouse, 2006.

Lamouroux, J., De Mey, P., Lyard, F., and Jeansou, E.: Study of the MOG2D model sensitivity to high frequency atmospheric forcing in the Bay of Biscay, and assimilation of altimetric and tidegauge observations in order to correct the model for the deficiencies of the atmospheric forcing fields, Mercator Ocean Quarterly Newsletter, 23, 5-14, 2006.

Legeais, J.-F., Ablain, M., and Thao, S.: Evaluation of wet troposphere path delays from atmospheric reanalyses and radiometers and their impact on the altimeter sea level, Ocean Sci., 10, 893905, doi:10.5194/os-10-893-2014, 2014.

Mathers, E. L. and Woodworth, P. L.: Departure from the local inverse barometer model observed in altimeter and tide gauge data and in a global barotropic numerical model, J. Geophys. Res. 106, 6957-6972, 2001.

Mourre, B.: Etude de configuration d'une constellation de satellites altimétriques pour l'observation de la dynamique océanique côtière, PhD, University Paul Sabatier, Toulouse, 2004.

Ponte, R. M. and Gaspar, P.: Regional analysis of the inverted barometer effect over the global ocean using Topex/Poseidon data and model results, J. Geophys. Res., 104, 15587-15601, 1999.

Ponte, R. M. and Ray, R. D.: Atmospheric Pressure Corrections in Geodesy and Oceanography: a strategy for handling air tides, Geophys. Res. Lett., 29, 2253-2256, doi:10.1029/2002GL016340, 2002.

Ray, R.: A global ocean tide model from Topex/Poseidon altimetry: GOT99.2, NASA Tech Memo 209478, 58 pp., 1999.

Ray, R. D. and Ponte, R. M.: Barometric tides from ECMWF operational analyses, Ann. Geophys., 21, 1897-1910, doi:10.5194/angeo-21-1897-2003, 2003.

REAPER: Product Handbook for ERS Altimetry Reprocessed Products, https://earth.esa.int/documents/10174/1511090/ Reaper-Product-Handbook-3.1.pdf (last access: 21 August 2014), 2014.

SSALTO/DUACS: User Handbook: (M)SLA and (M)ADT Near-Real Time and Delayed Time Products, http: //www.aviso.altimetry.fr/en/data/product-information/ aviso-user-handbooks.html (last access: 30 June 2015), v4.4, 2015.

Stammer, D., Wunsch, C., and Ponte, R. M.: De-aliasing of global high frequency barotropic motions in altimeter observations, Geophys. Res. Lett., 27, 1175-1178, 2000.

Thorne, P. W. and Vose, R. S.: Reanalyses Suitable for Characterizing Long-Term Trends, B. Am. Meteorol. Soc., 91, 353-361, doi:10.1175/2009BAMS2858.1, 2010.

Valladeau, G., Legeais, J.-F., Ablain, M., Guinehut, S., and Picot, N.: Comparing Altimetry with Tide Gauges and Argo profiling floats for data quality assessment and Mean Sea Level studies, Mar. Geod., 35, suppl. 1, 42-60, doi:10.1080/01490419.2012.718226, 2012.

Vinogradova, N. T., Ponte, R. M., and Stammer, D.: Relation between sea level and bottom pressure and the vertical dependence of oceanic variability, Geophys. Res. Lett., 34, L03608, doi:10.1029/2006GL028588, 2007.

Webb, D. J. and de Cuevas, B. A.: An ocean resonance in the Southeast Pacific, Geophys. Res. Lett., 29, 931-933, 2002a. 
Webb, D. J. and de Cuevas, B. A.: An ocean resonance in the Indian sector of the Southern ocean, Geophys. Res. Lett., 29, 16641667, doi:10.1029/2002GL015270, 2002b.

Webb, D. J. and de Cuevas, B. A.: The region of large sea surface height variability in the southeast Pacific Ocean, J. Phys. Oceanogr., 33, 1044-1056, 2003.
Willebrand, J., Philander, S., and Pacanowski, R.: The oceanic response to large-scale atmospheric disturbances, J. Phys. Oceanogr., 10, 411-429, 1980.

Willis, J. K. and Church, J. A.: Regional sea-level projection, Perspect. Sci., 336, 550-551, 2012. 